\title{
Study on the Tensile Creep Model of the Admixture of Early-Age Concrete and Application Simulation
}

\author{
Qin Keli ${ }^{1}$, Duan Yajuan ${ }^{2}$ and Guo Lixia ${ }^{2, *}$ \\ ${ }^{1}$ HeNan Vocational College of Water Conservancy and Environment, Zhengzhou 450045, China; ${ }^{2}$ North China Univer- \\ sity of Water Resources and Electric Power, Zhengzhou 450045, China
}

\begin{abstract}
With respect to the recent issue related to the lack of research on tensile creep model of the admixture concrete at early age and simulation, the admixture influence function with factor of the admixture dosage was established based on composite exponential function as reference model based on existed creep rules and appropriate assumption. It has been proposed that contributing factor, c, quantitatively represented the sensitivity of concrete creep changes to the admixture and correlation between concrete creep and the admixture. The model fitting was then made after tensile creep experiment by adding different admixtures such as fly ash, slag, silica fume and polypropylene fiber in contract to reference concrete test. It indicated that the model exhibited a good fitting performance, which is practical and useful as well as readily adopted by simulation. Meanwhile, the contributing factor also demonstrated quantitatively the variation among the effect of the admixtures (fly ash, slag, silica fume and polypropylene fiber) on the tensile creep of the concrete. Finally, the model was applied to an as-built concrete project for extended simulation, the results indicated that tensile creep can effectively improve the distribution of surface tensile stress and alleviate detrimental effect due to day-night temperature differences.
\end{abstract}

Keywords: Admixture, concrete, early age, prediction model, tensile creep, tensile stress.

\section{INTRODUCTION}

Recently, admixture has been used in almost all hydraulic concrete projects, such as fly ash concrete, slag concrete, fiber concrete and etc. In addition, its advantage in engineering and performance has been well studied. However, in terms of temperature control and crack prevention in concrete project, the major concern to the researchers lies on two aspects. One is replacing cement with mineral admixture can reduce the heat of hydration of concrete, such as fly ash concrete $[1,2]$. The other is admixture can improve mechanical behavior of concrete, such as polypropylene fiber reinforced concrete. This paper focuses on the effect of admixture on tensile creep of early-age concrete.

As the concept of early age in the domain of concrete materials is still unclear, the term 'early age' is used to describe concrete which is one week or less in age for convenience in this paper, considering from the perspectives of temperature control and crack prevention. In recent years, there have some studies devoted to the tensile creep of earlyage concrete using experiment, modeling and simulation at home and abroad. Interiorly, Experimental investigation and prediction research on the tensile creep of high performance concrete (HPC) at early age by Yang yang's team [3,4]. Experimental study, theoretical analysis and simulation research on tensile creep test of early-age concrete had been undertaken by Ju Yuwen and Li Kefei, et al. [5,6]. At overseas, tensile creep behavior of the admixture concrete had been studied by Kovler [7], I. Pane and W. Hansen [8]. Prediction model of tensile creep of early-age concrete and calculation had been studied by R. Faria [9]. These studies had provided good theoretical basis for understanding of tensile creep behavior of early-age concrete. However, these studies still had shortcomings. For example, most prediction models focused on improvement of compressive creep model $[3,9,10]$. Studies on the effect of the admixture on tensile creep of concrete mostly constrained on qualitative analysis $[7,8]$ and the lack of unified prediction model and quantitative evaluation criterion. It is also noted that the study on the effect of tensile creep on hydraulic concrete structure is also rarely reported. Therefore, this paper carried out investigation on tensile creep of the admixture concrete based on available research results, starting with building the prediction model, experiment, fitting analysis of modeling and simulation, in order to validate the model and quantitative evaluation of the effect of the admixture on the tensile creep of the concrete and sensitivity, as well as the influence of tensile creep on surface mechanical properties of early age concrete.

\section{TENSILE CREEP MODEL AND EXPERIMENT}

\subsection{Prediction Model Building}

For creep, any set of measured data can be fitted by functions such as hyperbolic function, power function and exponential function on the basis of research results at present. Such methods had been used in the study before ${ }^{[4]}$. Ross proposed a prediction model using hyperbolic function in 1937 which is still in use now. But even so, the precision 
fitted by a single curve is not high in simulation application due to different influencing factors or conditions, leading to great difference in fitting parameters for the same concrete.

Therefore, this paper assumes there are certain rules to follow for the same concrete after given prediction model of tensile creep at reference condition compared to the changes induced by changing one factor.

Therefore, with respect to the same concrete, this paper assumes there are certain rules to follow for the changes induced by changing one factor after given prediction model for tensile creep compared to the status of the model at reference condition. Based on this assumption, prediction model of tensile creep coefficients is given below.

$\varphi(t, \tau)=\varphi_{r}(t, \tau) \cdot \prod_{i=1}^{n} f_{i}\left(k_{i}\right)$

where $\varphi(t, \tau)$ is the simulation model predicting tensile creep coefficients, $\varphi_{\gamma}(t, \tau)$ is the reference model of tensile creep coefficients, $f_{i}\left(k_{i}\right)$ is the influence function of the $i$-th contributing factor, $k_{i}$ is the constant of the $i$-th contributing factor, $t$ is the age of concrete, day, $\tau$ is the loading time, day, $n$ is the total number of influencing factors to be considered.

According to available research results about tensile creep, $\phi_{\gamma}(t, \tau)$ in the Eq.(1) can be fitted simply by functions or further by basic creep parameters model such as BP model and MC90 model considering appropriate correction. In this paper, compound exponential function was chosen as reference model.

$$
\phi_{r}(t, \tau)=1-\exp \left[-a(t-\tau)^{b}\right]
$$

where $\mathrm{a}$ and $\mathrm{b}$ are model parameters determined by fitting of data, the remaining variables hold the same meanings as that in Eq.(1).

The effect of the dosage of the admixtures, which include fly ash, slag, silica fume and polypropylene fibers, will be studied in this paper. As the content of admixture dosage is usually expressed as percentage, the percentage of the admixture is selected as contributing factor. Considering that the value of the model is identically equal to 1 when there is no admixture, the influence function is built and given as follows.

$$
f_{i}\left(k_{i}\right)=\left[1+c \times k_{i}\right] \cdot g(t)
$$

where $k_{i}$ is the percentage of the admixture dosage, $\mathrm{c}$ is the contributing factor of the admixture determined by the experiment, $g(t)$ is the correction term of concrete age in order to remain the reference model unchanged (that is, to keep generality of the model) when the mechanical properties of reference concrete changes dramatically due to the use of some admixtures. So $\mathrm{g}(\mathrm{t})$ will be always 1 when $k_{i}$ is equal to zero.

It should be noted that $\mathrm{c}$ may be positive or negative depending on the effect of the admixture on the creep. There is a positive correlation between creep coefficient and admixture dosage; when there is a negative correlation between them when it is negative. That is, the higher content of the admixture, the greater creep coefficient when $\mathrm{c}$ is positive. The lower content of the admixture, the greater creep coeffi- cient when $\mathrm{c}$ is negative. In addition, the absolute value of $\mathrm{c}$ represents the creep coefficient sensitivity of concrete subject to the admixture. The higher the absolute value of $\mathrm{c}$, the more sensitive the creep coefficient.

\subsection{Tensile Creep Experiment and Model Fitting}

Concrete specimens have been prepared in accordance with national standard test method, with dimension of 1000 $\mathrm{mm} \times 100 \mathrm{~mm} \times 100 \mathrm{~mm}$. After specimen moulding and demoulding, the specimens for tensile creep test and shrinkage compensation test were sealed with aluminum foil immediately to prevent water loss. Measurement of autogenous shrinkage deformation of concrete started at age of $24 \mathrm{~h}$ for shrinkage compensation test. End restrained method was applied to tensile creep test. In order to obtain the influence of various admixtures on tensile creep of concrete at early age, there are 17 specimens divided into 4 groups. Among them, there is 1 specimen chosen for reference concrete test, the proportion of which is listed in Table $\mathbf{1}$ with water-binder ratio of 0.4 .

Part of concrete was replaced by fly ash, slag, silica fume and polypropylene fiber for the remaining 16 specimens in 4 groups. There were 4 specimens in each group. For each group, admixture dosage and experimental results have been shown in Fig. (1).

In order to model fitting, according to experimental results of reference concrete specimen at first, parameters a and b were 0.425 and 0.456 , respectively, as shown in Fig. (1) and Table 3. The correlation coefficient was 0.99 . And on this basis parameter $\mathrm{c}$ can be fitted according to experimental results for remaining 4 groups (fly ash, slag, silica fume and polypropylene fiber). In the fitting process, $g(t)$ was assumed to be 1 at first and correction would be applied only when a considerable deviation occurred. The fitting results were presented in Table 2.

As shown in Table 2, fly ash and slag have negative effect on the early age creep of concrete. That is, the more dosage of these admixtures, the lesser the early age tensile creep of concrete became. It is consistent with the research findings of I. Pane et al. [8]. Moreover, tensile creep was slightly more sensitive to fly ash than slag. Contrary to influence of fly ash and slag, silica fume can increase the tensile creep of concrete. It was consistent with research findings of Kovler et al. [7] and I. Pane et al. [8]. And compared with the influence of fly ash and slag, tensile creep of concrete is more sensitive. It was also noted that polypropylene fiber significantly decreased the early age tensile creep of concrete, which exhibited high sensitivity. Table 3 shows that the correlation coefficients after fitting at different dosages for various admixtures were above 0.96 even up to 0.99 . The integrated correlation coefficients for different admixtures were above 0.98 , which indicated a good correlation between the model and experimental data. Fig. (1) shows that tensile creep coefficients illustrated by fitting curve using this model had fully reflected actual measured rules and the coefficients at age of 1 to $7 \mathrm{~d}$ were basically consistent. 
Table 1. Experimental proportion of concrete.

\begin{tabular}{|c|c|c|c|c|c|c|}
\hline \multirow{2}{*}{\begin{tabular}{|c|c|} 
Proportion No. \\
\cline { 2 - 7 }
\end{tabular}} & \multicolumn{5}{|c|}{ Dosage for each material in concrete $\left(\mathbf{k g} / \mathbf{m}^{3}\right)$} & W/C ratio \\
\cline { 2 - 7 } & Water & Cement & River sand & Gravel & Water-reducer & $0.4 \%$ \\
\hline \hline RC & 195 & 488 & 601 & 1116 & 0.40 \\
\hline
\end{tabular}

Notes: $\mathrm{W} / \mathrm{C}$ ratio=water-cement ratio

Table 2. C value and fitting results of $g(t)$.

\begin{tabular}{|c|c|c|c|c|}
\hline Testing group & Fly ash & Slag & Silica fume & polypropylene fiber \\
\hline \hline$c$ value & -1.36 & -1.25 & 4.15 & -26.25 \\
\hline$g(t)$ & 1 & 1 & 1 & $1-\exp (-1.4 t)$ \\
\hline
\end{tabular}

Table 3. Correlation coefficients based on model fitting.

\begin{tabular}{|c|c|c|c|c|c|c|c|c|}
\hline \multirow{2}{*}{ Specimen No. } & \multicolumn{2}{|c|}{ Fly ash } & \multicolumn{2}{|c|}{ Slag } & \multicolumn{2}{|c|}{ Silica fume } & \multicolumn{2}{|c|}{ Polypropylene fiber } \\
\hline & Dosage $k_{1}$ & $\begin{array}{c}\text { Correlation } \\
\text { coefficient }\end{array}$ & Dosage $\mathbf{k}_{2}$ & $\begin{array}{c}\text { Correlation } \\
\text { coefficient }\end{array}$ & Dosage $k_{3}$ & $\begin{array}{c}\text { Correlation } \\
\text { coefficient }\end{array}$ & Dosage $\mathbf{k}_{4}$ & $\begin{array}{c}\text { Correlation } \\
\text { coefficient }\end{array}$ \\
\hline Reference & $0 \%$ & 0.989 & $0 \%$ & 0.989 & $0 \%$ & 0.989 & $0 \%$ & 0.989 \\
\hline 1 & $10 \%$ & 0.988 & $10 \%$ & 0.974 & $5 \%$ & 0.986 & $0.6 \%$ & 0.983 \\
\hline 2 & $20 \%$ & 0.993 & $20 \%$ & 0.972 & $10 \%$ & 0.982 & $0.9 \%$ & 0.987 \\
\hline 3 & $30 \%$ & 0.991 & $30 \%$ & 0.985 & $15 \%$ & 0.977 & $1.2 \%$ & 0.989 \\
\hline 4 & $40 \%$ & 0.979 & $40 \%$ & 0.961 & $20 \%$ & 0.985 & $1.5 \%$ & 0.979 \\
\hline $\begin{array}{l}\text { Integrated } \\
\text { correlation } \\
\text { coefficient }\end{array}$ & \multicolumn{2}{|c|}{0.989} & \multicolumn{2}{|c|}{0.983} & \multicolumn{2}{|c|}{0.983} & \multicolumn{2}{|c|}{0.985} \\
\hline
\end{tabular}

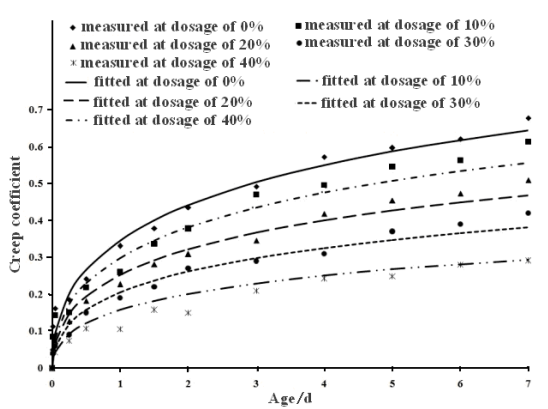

(a) Fly ash

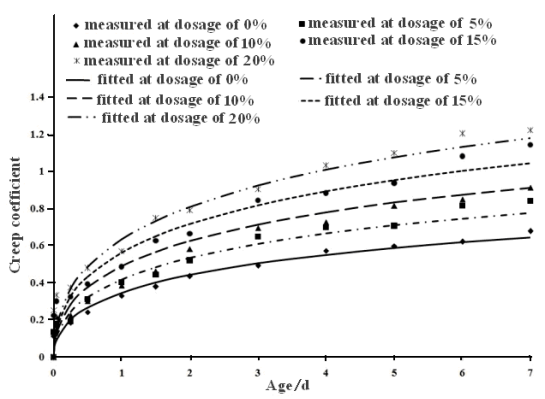

(c) Silica fume

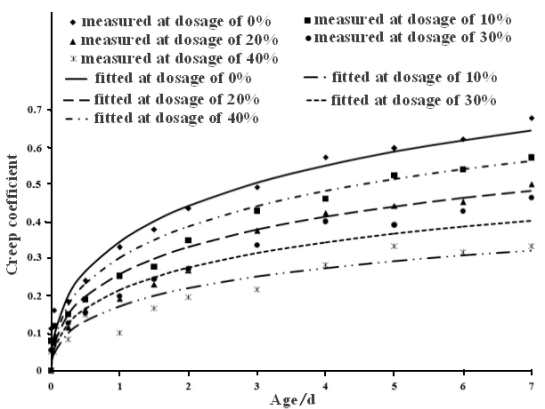

(b) Slag

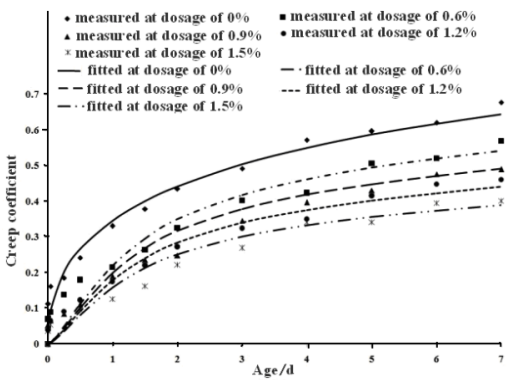

(d) Polypropylene fiber

Fig. (1). Fitting results of creep coefficient for different admixtures. 
It is worth mentioning, in fitting duration of polypropylene fiber group, when $g(t)$ was assumed to be 1 , the fitting results was not good, as shown in Fig. (2) When the dosage of polypropylene fiber was $1.5 \%$, there was no big different for fitting results after the age of 3 days considering the fitted value of $g(t)$ or not. However, there would be a greater deviation between fitting value of the creep coefficient and the measured value if without considering the fitting value of $g(t)$ in first three days. Compared with this, taking account of the fitting value of $g(t)$ for the first three days can better reflect the variation trend of measured value. When the dosage of polypropylene fiber changed, the similar findings as mentioned just above also can be observed, but it was found that the higher dosage resulted in more pronounced deviation. The authors believed that the phenomenon may be due to adding of polypropylene fiber which caused significant changes in mechanical properties of concrete during the first three days. It is basically consistent with the conclusions of studies on polypropylene fiber reinforced concrete at present. It should be noted here that $\mathrm{g}(\mathrm{t})$ associated with polypropylene fiber was not equal to 1 and in order to ensure the universality of the model, the value of $g(t)$ was not considered if polypropylene fiber was not added in the process of simulation.

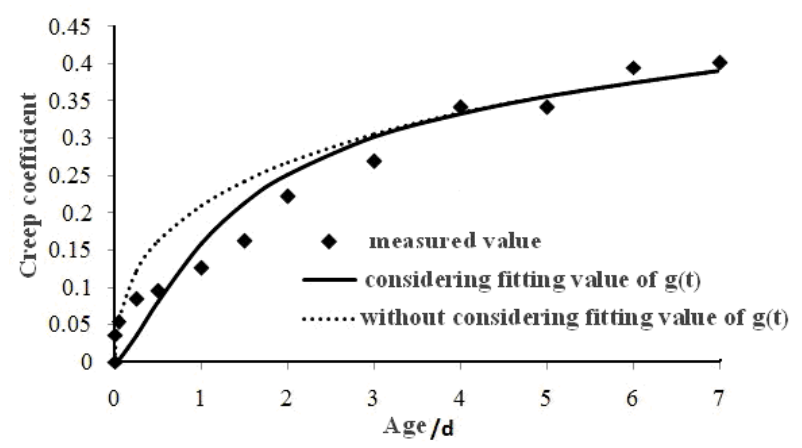

Fig. (2). Comparison between Two Scenarios for Polypropylene Dosage at $1.5 \%$

\section{EXTENDED ENGINEERING APPLICATIONS}

\subsection{Introduction of Previous Studies}

As we known, stress relaxation evolved from creep can be beneficial in form of temperature control and crack prevention for concrete. At present, studies in the field of simulation mainly focus on compressive creep. Little attention has been paid to the effect of tensile creep particularly at early age. On basis of model research in this paper, Huaiyin No.3 Pumping Station project was used as a case to study the cracking problem due to early age tensile creep.

Huaiyin No. 3 Pumping Station project is one of the third cascade pumping stations in eastern route of SouthNorth Water Transfer (SNWT) project. It is a bulb type tubular pumping station using a complicated structure form and its pier thickness varies greatly. Tensile creep was not considered on the study of this pumping station in terms of temperature control and crack prevention [11,12]. Content of fly ash was $15 \%$ in proportion of pier in the pumping station[12]. According to Eq. (3) and Table 2, $\mathrm{f}(\mathrm{k} 1)=0.796$ can be obtained. The creep model of this project can be determined by Eq. (1) and (2) as follows.

$$
\varphi(t, \tau)=0.796 \times\left[1-\exp \left(-0.425(t-\tau)^{0.456}\right)\right]
$$

\subsection{Calculation and Analysis}

Calculation model, conditions and simulation principle were the same as those in literatures $[1,12]$ but the difference was tensile creep term was added to original strain increment equation and there was a linear relation between tensile creep deformation and stress and Boltzman superposition principle can be followed in the process of tensile creep calculation. It was important to note that both compressive creep and tensile creep were related to concrete stress state and they cannot coexist simultaneously. Therefore, creep type would be selected automatically based on principal stress state at previous moment when programming. In addition, decreasing step was adopted in order to reduce errors induced by conversion of compressive stress and tensile stress during calculation. The step was assigned to be $0.125 \mathrm{~d}$ in the calculation.

For sake of convenience, the pier was chosen as research object. Taking account of the basic rule that tension occurs at surface and compression occurs inside the concrete at early age, analysis of the effect of tensile creep only focused on the surface stress state of pier concrete. Those not mentioned can be referred to the literature [12]. Calculation results were shown in Figs. (3 and 4). Fig. (3) presented the time-history curve of the major principal stress at points on the pier surface under the two scenarios (the surface point corresponded to b3 point in the literature [12]). Fig. (4) illustrated the anticracking safety comparison between the two scenarios. In this paper, anti-cracking safety was defined as the ratio of the tensile strength to the tensile stress of concrete at the same age.

The calculation results indicated that, the surface stress difference under the two circumstances was great when the calculation results of temperature field remained unchanged. It was noted that the changes in the surface tensile stress subjected to the same temperature difference between day and night was moderate. Conspicuously, amplitude of the stress fluctuation was smaller compared to the circumstance that no consideration of the tensile creep. Meanwhile, due to relaxation induced by tensile creep, tensile stress decreased. The maximum tensile stress was $0.72 \mathrm{MPa}$. The anticracking safety of 1.74 at the most dangerous moment occurred on around the age of $2 \mathrm{~d}$. Under no consideration of the tensile creep, the maximum tensile stress can be up to $0.95 \mathrm{MPa}$ and minimum anti-cracking safety was as low as 1.2. According to the importance of the project, allowable anti-cracking safety was required to reach the value of 2 . It means there were 16 hours per day at risk of cracking when no consideration of the tensile creep but only 9 hours per day at risk of cracking when considering the tensile creep during the first 4 days after concrete pouring.

Therefore, surface tensile stress distribution of concrete would be improved when considering tensile creep. The stress during the first 4 days can decrease by an average of $14 \%$ and the adverse effect because of temperature different between day and night can be alleviated to a certain extent. 
Maximum daily amplitude of the stress fluctuation decreased from $0.42 \mathrm{MPa}$ without considering tensile creep to $0.24 \mathrm{MPa}$. in addition, the cracking risk of the concrete was also reduced.

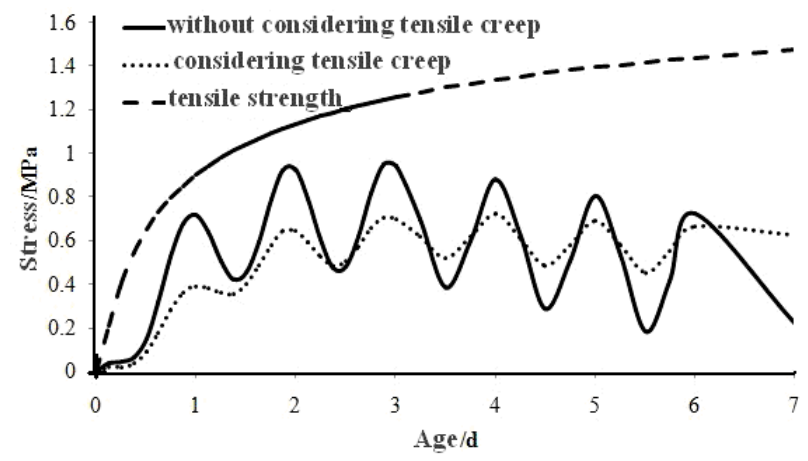

Fig. (3). Time-history of The Major Principal Stress in Two Cases.

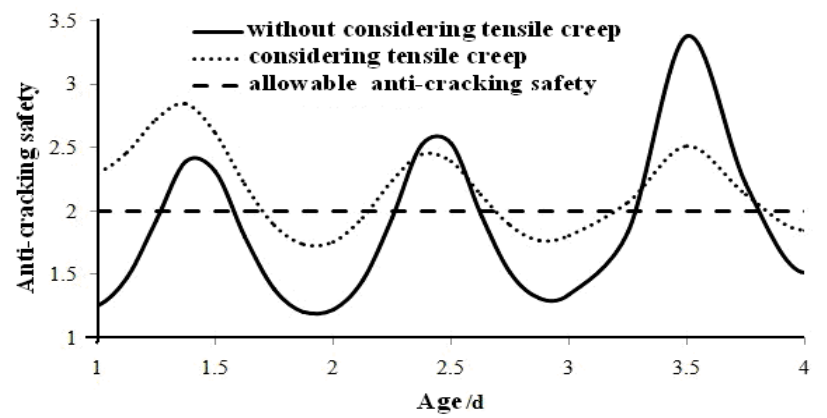

Fig. (4). Anti-cracking Safety of Concrete in Two Cases during The First 4 Days.

\section{CONCLUSION}

This paper built the basic equation of tensile creep coefficient based on available research results about creep. Next, the admixture influence function with factor of the admixture dosage was established based on composite exponential function as reference model. Specifically, contributing factor represented the sensitivity of concrete creep changes to the admixture and correlation between concrete creep and the admixture. The effect of the various admixtures on the concrete creep was analyzed quantitatively.

The model fitting was made after concrete creep experiment by adding different admixtures such as fly ash, slag, silica fume and polypropylene fiber. It indicated that the model exhibited a good fitting performance, which is practical and useful as well as readily adopted by simulation. Meanwhile, the negative effects of fly ash, slag and polypropylene and positive effect of silica fume on concrete creep had been quantitatively illustrated. It was noted that, the sensitivities of concrete creep to polypropylene fiber, fly ash, slag and silica fume were up to $-26.25,-1.36,-1.25$ and 4.15 , respectively.
On basis of authors' previous studies, tensile creep model was applied in the temperature control simulation of Huaiyin No.3 Pumping Station project. The basic idea of the application was adding term of tensile creep strain to conventional strain increment equation and implementation by computer program which can easily consider the effect of tensile creep based on linear relation between tensile creep deformation and stress as well as superposition principle. By simulation and comparative analysis, it was shown that surface tensile stress of pier during the first 4 days can decrease by an average of approximate $14 \%$ and detrimental effect due to daynight temperature differences can be alleviated effectively when considering tensile creep compared with the scenario that tensile creep was not considered.

\section{CONFLICT OF INTEREST}

The authors confirm that this article content has no conflict of interest.

\section{ACKNOWLEDGEMENTS}

This work is supported by National Natural Science Foundation of China (No. 51109081).

\section{REFERENCES}

[1] B. Zhu, The Mass Concrete Temperature Stress and Temperature Control, China Water Conservancy and Hydropower Press, Beijing, 2012.

[2] X. Li, X. Ma, and Z. Han, "Workability and Mechanical Properties of Polypropylene Fiber Reinforced Concrete," Journal of Wuhan University of Technology, vol. 31, no. 5, pp. 9-12, 2009.

[3] Y. Yang, S. Xu, and D. Ye, "High Strength Concrete Tensile Creep Properties", Journal of Silicate, vol. 37, no. 7, pp. 1124-1129, 2009

[4] D. Ye, "High Performance Concrete Tensile Creep Research," Zhejiang University of Technology, 2008

[5] Y. Ju, K. Li, and J. Han, "Early Age Concrete Tensile Creep Test and Theoretical Study", Engineering Mechanics, vol. 26, no. 9, pp. 43-49, 2009

[6] Y. W. Ju, K. Li, and J. Han, "Early-age Stress Analysis of Concrete Diaphragm Wall through Tensile and Compressive Creep Modeling”, Engineering Mechanics, vol. 26, no. 11, pp. 80-87, 2009.

[7] K. Kovler, S. Igarashi, and A. Bentur, "Tensile Creep Behavior of High Strength Concretes at Early Ages," Materials and Structures, vol. 32 , pp. 383-387, 1999

[8] I. Pane, and W. Hansen, "Early Age Creep and Stress Relaxation of Concrete Containing Blended Cement," Materials and Structures, vol. 35, pp. 92-96, 2002.

[9] R. Faria, M. Azenha, and J. A. Figueiras, "Modeling of Concrete at Early Ages: Application to An Externally Restrained Slab," Cement and Concrete Composites, vol. 28, no. 6, pp. 572-585, 2006.

[10] Z. P. Bazant, and J. S. Bwe, "Creep and Shrinkage Prediction Model for Analysis and Design of Concrete Structures model B3," Materials and Structures, vol. 28, pp. 357-365, 1995.

[11] Z. P. Bazant, and J. S. Bwe, "Justification and Refinement of Model B3 for Concrete Creep and Shrinkage," Materials and Structures. vol. 28, pp. 88-495, 1995.

[12] S. Chen, S. Qiang, and L. Guo, "Numerical Analysis of Concrete Temperature and Stress in Tubular Channel of Huaiyin 3rd Pumping Station", Water Resources and Hydropower Engineering, vol. 42 , no. 1 , pp. 44-47, 2011. 